$1-1-1954$

\title{
Pricing medium and large eggs relatively for maximum value
}

Norman Nybroten

Follow this and additional works at: https://researchrepository.wvu.edu/ wv_agricultural_and_forestry_experiment_station_bulletins

\section{Digital Commons Citation}

Nybroten, Norman, "Pricing medium and large eggs relatively for maximum value" (1954). West Virginia Agricultural and Forestry Experiment Station Bulletins. 367.

https://researchrepository.wvu.edu/wv_agricultural_and_forestry_experiment_station_bulletins/361 @ WVU. It has been accepted for inclusion in West Virginia Agricultural and Forestry Experiment Station Bulletins by an authorized administrator of The Research Repository @WVU. For more information, please contact ian.harmon@mail.wvu.edu. 


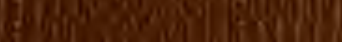

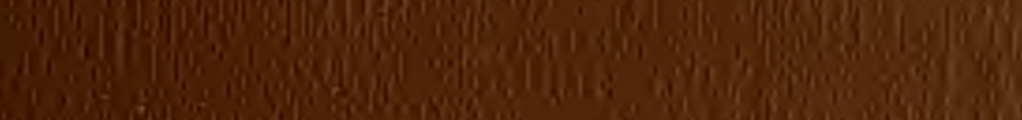

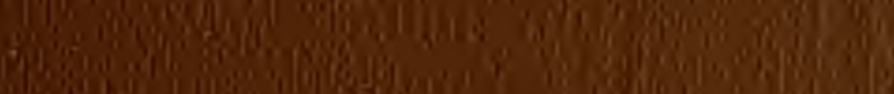
(1)

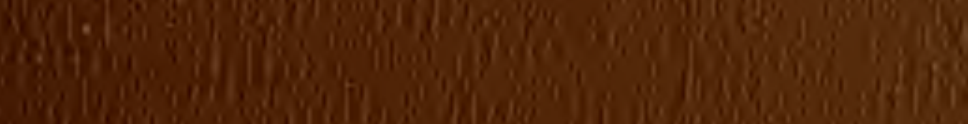

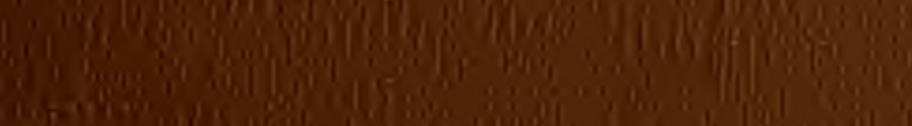

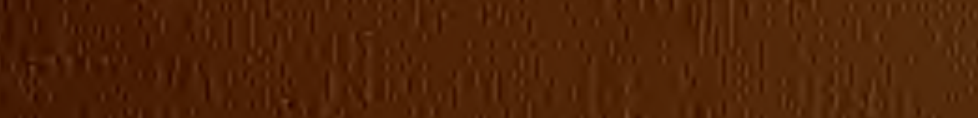

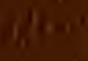

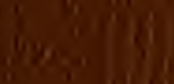

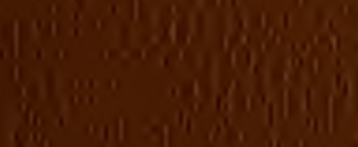

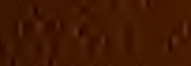
. - 1 ing

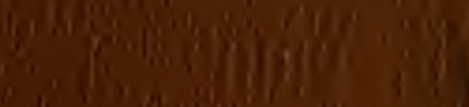
I

\section{axts}

wantions

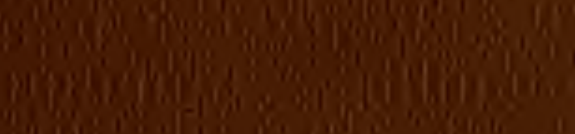

Nin:

$3_{1} 1$ (1) 
Digitized by the Internet Archive in 2010 with funding from

Lyrasis Members and Sloan Foundation 


\section{ricing Medium and Large Eggss Relatively For Maximum Value}

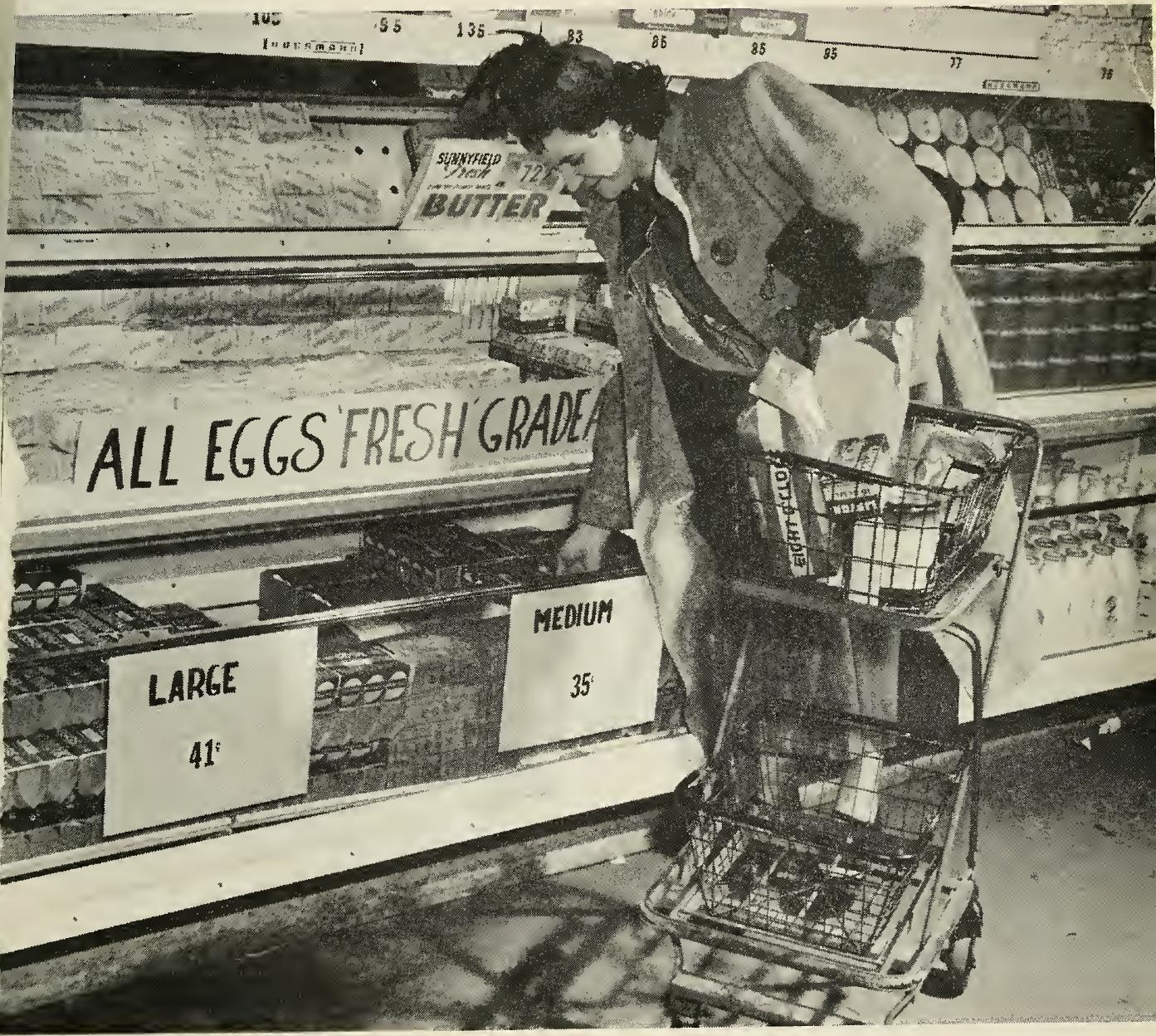

Bulletin 367

June 1954

WEST VIRGINIA UNIVERSITY AGRICULTURAL EXPERIMENT STATION 


\section{Summary and Conclusions}

Retail experiments and opinion surveys in West Virginia cities show that egg sales can be increased if Medium and Large cggs are logically priced in terms of each other. The pricing must take into consideration both consumers' ideas on the relative values of Medium and Large eggs as well as the relative supplies of the two sizes. When this is done, it is possible to keep both sizes in the display continuously-thus increasing the value of the eggs.

The egg handler-whether he be a retailer, jobber, or wholesaler-can gain by using more definite pricing methods. A formula and a chart showing consumers' reactions and ideas is included in this report. Egg handlers desiring to do so could plot their own data on relative sales at different price relationships between Medium and Large eggs. They could thus learn to cater more closely to consumers in the community involved.

\section{THE AUTHOR}

NORMAN NYBROTEN is Agricultural Economist at the West Virginia University Agricultural Experiment Station and Professor of Agricultural Economics in the College of Agriculture, Forestry, and Home Economics.

\section{ACKNOWLEDGEMENT}

This work was partly supported by funds from the Research and Marketing Act of 1946 and is in support of research in the Northeast Region.

West Virginia UNIVERSITY

Agricultural EXPERIMENT Station

College of Agriculture, Forestry, and Home Economics

H. R. VARNEY, Director 


\section{Pricing Medium and Large Eggs Relatively For Maximum Value}

NORMAN NYBROTEN

THE food retailer, along with other egg handlers, is faced with the 1 problem of supplying egg sizes wanted by his customers. In some instances he has opportunity to order varying amounts of each size at quoted prices. In such cases he has the problem of determining how many eggs of each size he can sell at prices based on those quoted. In other instances he buys or produces nest-run eggs that yield certain amounts of each size. Then he should price the sizes so that the eggs will clear the market in about the same amount of time.

This problem was studied in two different ways. First, Medium and Large eggs were sold at retail under six price relationships between the two sizes. The experiment was designed to eliminate any effect on price other than size. Medium eggs were sold at different times for either $70,75,80,85,90$, or 95 per cent of the price of Large eggs. The Medium eggs weighed about 22 ounces per dozen and Large eggs about 25 ounces. All eggs were grade A. More than five thousand identified customers selected one of the two sizes offered at these planned price relationships. Second, people, selected by chance, were asked to give opinions on their ideas of the value of Medium and Large eggs. Opinions were received from about five thousand homemakers, 986 of whom were identified as having been customers in the retail experiment.

\section{People Differ in Price Ideas}

Figure 1 shows results of the experiment and the opinion survey. In the experiment larger percentages of the sales were of Medium eggs when they were priced at lower percentages of Large. For example, when Medium eggs were priced at 70 per cent of Large, about two-thirds of the eggs sold were Medium, compared with about one-third when priced at 95 per cent of Large.

Changes in the price relationship between Medium and Large eggs brought about shifts in the relative sales of the two sizes. The shifts were not as great, however, as might have been anticipated from the opinions given by the sample of customers. According to the opinion 
survey, customers would have been much more sensitive to the differences in the price relationships. If Medium eggs were priced at 95 per cent of Large, only about one-tenth of the customers said they would buy Medium, whereas with Medium eggs priced at 70 per cent of Large, 95 per cent of the people would have preferred Large.

In the experiment every reasonable effort was macle to keep the eggs the same in every respect except for size and price. Besides the labeling shown in the cover photograph, an attendant was available to give information at all times. He was permitted to answer any question a customer might ask except which size would be the better buy. Even with these precautions, it is possible that customers were not entirely convinced that size and price were the only differences.

Observation of a customer in the store and study of successive egg purchases by the same individual under clifferent price relationships showed that many people evidently were not thinking about relative prices. Many, especially during rush hours, picked up eggs so hurriedly that it would have been virtually impossible for them to have given any consideration to the price relationship between Medium and Large eggs. In the survey, however, people were mentally "alerted" to think about the price relationship. This may be the principal reason for the difference between expressed opinions and behavior.

\section{Level of Egg Prices Affect Ideas}

About five thousand homemakers gave opinions on what they thought the price of Medium eggs should be when Large eggs were priced at 48,56 , and at 72 cents. If eggs were sold entirely on a weight basis, the price of Medium eggs would be about 89 per cent of the price of Large-since 22 ounces divided by 25 ounces equals .89 . On the average, homemakers were not far from this. They stated that they were willing to pay 12.7 per cent of the price of Large in order to get Large rather than Medium. (See Table 1.)

Table 1. Price Premum Homenakers Stated They Were Willing to Pay for Large Eggs Rather Than Medium at Three Different

Assumed Prices for LARGe

\begin{tabular}{|c|c|c|}
\hline $\begin{array}{l}\text { ASSUMED PRICE } \\
\text { FOR A DOZEN }\end{array}$ & PrEMIUM hOAEMAKERS STATED & THEY WERE WILLJNG TO PAY FOR LARGE \\
\hline LARGE EGGS - & AVERAGE CENTS & Percentage the average Premium \\
\hline IN CENTS & PER DOZEN & IS OF PRICE OF LARGE \\
\hline 48 & 6.8 & 14.3 \\
\hline 56 & 7.3 & 13.1 \\
\hline 72 & 7.7 & 10.7 \\
\hline Average & 7.3 & 12.7 \\
\hline
\end{tabular}


The average number of cents premium people stated they would : pay for Large rather than Medium varied slightly with the price of I eggs. However, this variation was not great enough to make the price of Medium a constant per cent of the price of Large. Generally they put the price of Medium at a higher per cent of the price of Large when egg prices are higher.

Probably one of the reasons people overprice Medium in comparison with Large eggs at higher egg prices and underprice them at lower prices, from the standpoint of the weights of the two sizes, is that many of them think in terms of a certain number of cents difference instead of basing the difference on relative weights. Only about one-tenth of the homemakers interviewed gave evidence of calculating the weight relationships to estimate the price relationship. To study this further, 163 homemakers, selected at random, were told that Medium eggs weigh about 22 ounces and Large 25 ounces per dozen. These homemakers were asked, "How do you think the price of a dozen Large-size eggs should compare with the price of a dozen Medium-price eggs?" Only 7 per cent gave a percentage relationship in their price estimates. Others, who gave a certain number of cents difference, may have thought in terms of egg prices at the time of the interview-in which case their basis for reasoning could not be determined.

The level of egg prices probably has some effect on how people think about the comparison of the price of Medium and Large eggs. In the retail experiment such effect was not great. In any event, it seems that the egg handler, even without more accurate knowledge, can gain by pricing the two sizes more in keeping with consumer ideas.

\section{Egg Handlers Can Help and Gain}

The retailer, as well as the jobber or wholesaler of eggs, can benefit by knowing the relative demands for egg sizes. He can benefit by learning how much to order of each size when the cost prices are quoted, and how to price the two sizes when they are purchased as mixed. Many egg handlers are uncertain as to whether to buy mixed-size lots and sort by size or buy separate sizes. Kuowing the relative demand for egg sizes helps answer this question.

If prices of the two sizes are quoted to a retailer, his problem is relatively simple. He then need learn only how many of each size he can expect to sell at a given price relationship. Take for example a retailer who can buy Large at 69 cents and Medium at 49 cents and wants a 10-cent gross margin. The price of Medium would then be about 75 per cent of Large-Medium 59 cents and Large 79 cents. According to the data from actual sales shown in Figure 1, he would order about 55 


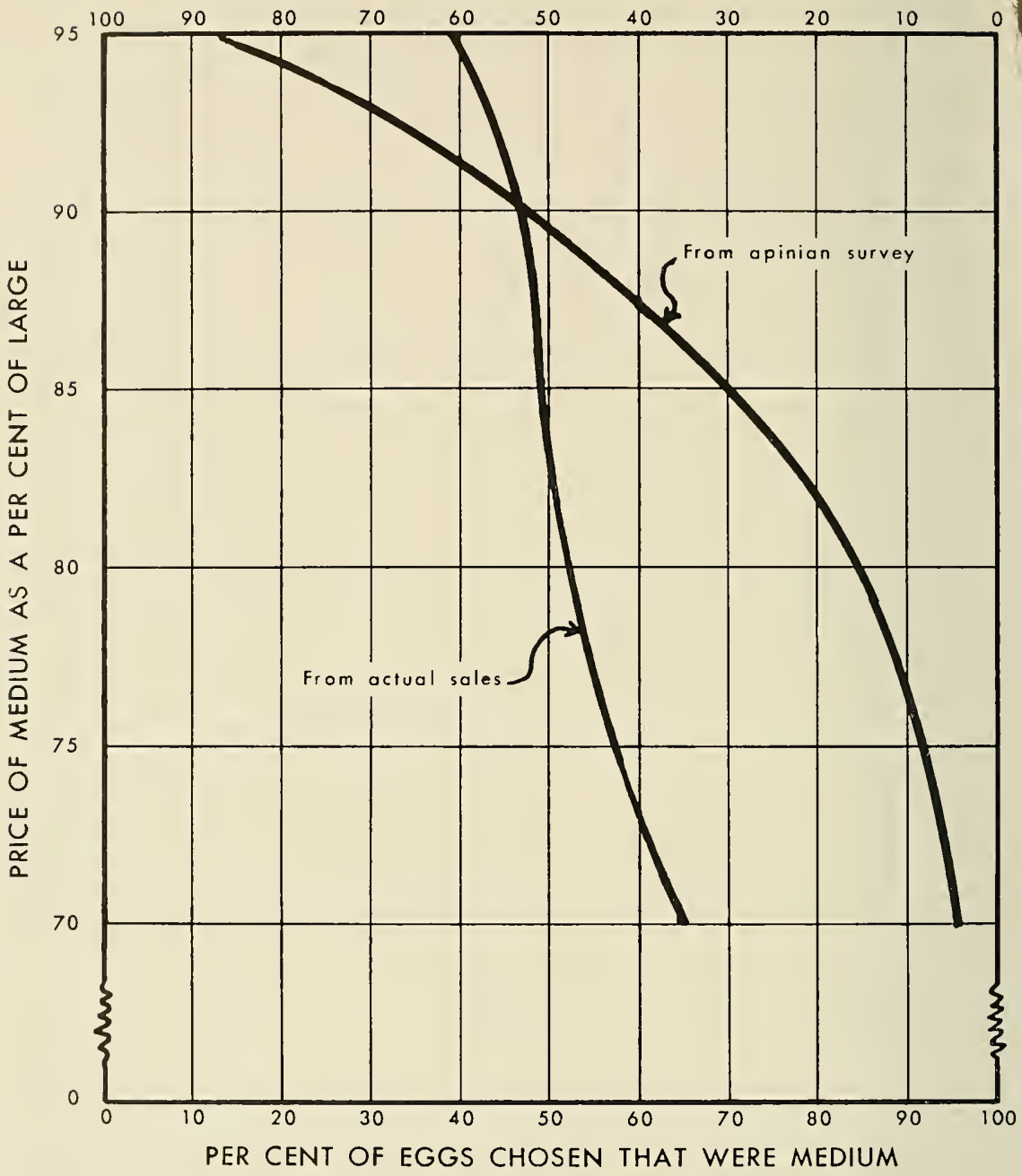

FIGURE 1. Per cent of egg sales that were Medium and per cent Large at varying price relationships compared with customers opinions on value of two sizes.

per cent Medium and 45 per cent Large. On the opinion basis shown in the figure he would order about 92 per cent Medium and 8 per cent Large. Conservatively, he might place his order somewhere near the middle of these two limits, at least until local experience might alter his judgment. 
If a retailer buys mixed-size eggs and wants to sell them as Medium at one price and Large at another, his problem is somewhat different, but it can be solved easily with the following formula-

$$
\begin{aligned}
& \begin{array}{l}
\text { Price of) } \\
\text { Large in) } \\
\text { dollars ) }
\end{array} \\
& \frac{\begin{array}{l}
\text { Per cent of eggs) } \\
\text { that are Medium) }
\end{array}}{\text { Per cent Medium } \begin{array}{c}
\text { Price should be } \\
\text { of price of Large }
\end{array}} \begin{array}{c}
\text { Per cent of } \\
\text { are Large } \\
100
\end{array}
\end{aligned}
$$

For example, if a retailer wants to average 59 cents a dozen on a mixed lot that yields 60 per cent Medium and 40 per cent Large, he can solve it as follows from the above formula:

$$
\begin{aligned}
& \begin{array}{l}
\text { Price of) } \\
\text { Large in) } \\
\text { dollars })
\end{array} \\
& \frac{60 \times 73+40}{100}
\end{aligned}=\frac{59}{43.8+40}=\frac{59}{83.8}=\$ .704
$$

The "73" was obtained from Figure 1 . The way this is clone is to place a straight edge on the per cent Medium (60 on this case) on the lower horizontal scale to the 40 per cent Large on the upper horizontal scale. This crosses the line "From actual sales" at a point that gives a reading (about 73 in this case) on the vertical scale at the left. This is the per cent the price of Medium ought to be of the price of Large. The price of Medium would then, of course, be $.73 \times \$ .704=\$ .514$. To check the results, multiply the percentages for each size by its respective price and add:

$$
\begin{aligned}
& 60 \times .514=30.840 \\
& 40 \times .704=28.160
\end{aligned}
$$

59.000 cents, which is the average price wanted for the mixed lots.

It should be noted that the mark-up must be made before the formula is applied. Also, if the eggs are to be priced at retail, the prices will have to be rounded to the penny-in which instance one would be rounded upward and the other downward to avoid fractions of cents. In sucls instances, results should be checked alter the prices have been rounded off. Since this check will then contain the "rounding error" it will usually not give exactly the average price, but it should be very near it.

In the foregoing illustration, the curve "From actual sales" was used to determine the price relationship, which resulted in Medium priced at 73 per cent of Large. If the curve "From opinion survey" had been used, Medium would have been priced at 87 per cent of Large. At first the egg handler may want to use some figure in between these- 
perhaps the average. If he would then chart his own relative volumes of the sizes, he could soon learn what percentages of each size he could expect to sell at various price relationships. He must not, of course, ignore his competition in his pricing.

The formula was used to determnie factors to multiply times the average price wanted for the mixed lot in order to obtain prices for Medium and Large eggs. Solutions for certain percentage yields of Medium eggs-assuming the remainder to be Large eggs-are shown in Table 2.

Table 2. Multipliers for Setting the Priges of Medium and Large Eggs in Relation to the Price of Mixed Lot,*

\begin{tabular}{|c|c|c|c|c|}
\hline \multirow{2}{*}{$\begin{array}{l}\text { PER CENT OF } \\
\text { THE MIXED } \\
\text { LOT THAT } \\
\text { SIZES OUT }\end{array}$} & \multicolumn{4}{|c|}{$\begin{array}{l}\text { MULTIPLIER TO USE TIMES THE AVERAGE PRICE TO BE RECEIVED FOR THE } \\
\text { MIXED LOT TO SET PRICES FOR MEDIUM AND LARGE }\end{array}$} \\
\hline & \multicolumn{2}{|c|}{ From ACTUAL SALES } & \multicolumn{2}{|c|}{ FROM OPINION SURVEY } \\
\hline as Medium & MEDIUM & LARGE & MEDIUM & LARGE \\
\hline 20 & $\mathrm{xx}$ & $\mathrm{xx}$ & .95 & 1.01 \\
\hline 30 & $\mathrm{xx}$ & $\mathrm{xx}$ & .95 & 1.02 \\
\hline 40 & .97 & 1.02 & .95 & 1.04 \\
\hline 50 & .92 & 1.08 & .94 & 1.06 \\
\hline 60 & .87 & 1.19 & .94 & 1.09 \\
\hline 70 & .88 & 1.29 & .95 & 1.12 \\
\hline 80 & $\mathrm{xx}$ & $\mathrm{xx}$ & .96 & 1.16 \\
\hline 90 & $\mathrm{xx}$ & $\mathrm{xx}$ & .97 & 1.25 \\
\hline
\end{tabular}

* These multipliers can be used for setting prices on Medium and Large when these two sizes come from a mixed lot that is substantially made up of these two size classes. For example, if a lot yields 60 per cent Medium and 40 per cent Large and the average price wanted is 50 cents per dozen, the way to use the table is as follows--

Find line of 60 iu first column and note that "from actual sales" the multipliers are .87 and 1.19. The prices would then be:

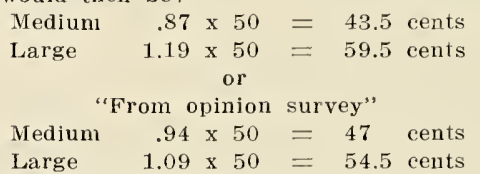

Either of the two sets of prices will average approximately 50 cents for the mixed lot as will also the average of the two sets.

\section{Sizing Has Its Advantages}

The main advantage of sorting eggs by size is to obtain a more clearly defined product. This gives the consumer opportunity to choose the size he wants. The retail experiment upon which part of this study is based shows that a more valuable product can be obtained through sizing, and sales can be increased.

The retailer is usually interested in not revealing his mark-up. If he is in a rural area with a local supply of nest-run eggs, the price farmers are receiving for eggs is usually common knowledge among his cus- 
tomers and egg suppliers. If he buys nest-run eggs and sells them as such, his customers will know his mark-up, but not so if he sorts them into classes of eggs and prices each class differently. For example, if he pays 50 cents for nest-run eggs that would yicld 68 per cent Mediun and 32 per cent Large, he could average a 10 -cent mark-up by pricing Mediun at 53 cents and Large at 75 cents a dozen (See Figure 1.) Local conditions may call for some adjustment in these prices. At least some of the retailers interviewed in a recent study indicated that they were interested in this feature of pricing.

Correct relative pricing of the sizes-that is, a price relationship that will sell the available amount of each size in the same length of timemakes it possible to have a continuous choice in the display without making intermittent purchases of only one of the two sizes. Intermittent purchases of either of the two sizes would tend to keep the other size in the store for a longer time and the eggs would not be as fresh. Availability of both sizes to the customers at all times should help increase sales. 


